\title{
Identifying and Prioritizing the Performance Criteria of Denim Washing Industry in Bangladesh Using Analytic Hierarchy Process
}

\author{
Md. Rezaul Karim, MSc \\ Prof. Md. Monirul Islam, MSc \\ Prof. Mohammad Ali, PhD
}

Bangladesh University of Textiles, Bangladesh

Doi:10.19044/esj.2020.v16n19p442ＵRL:http://dx.doi.org/10.19044/esj.2020.v16n19p442

\begin{abstract}
In the midst of the negative growth of textile and RMG industries, the mother industry of Bangladesh, the denim industry, has been doing its part incessantly. While the prospect of the denim industry looks promising from the last few years, the factors that drive this industry forward remain unanswered. Among the process chain of denim manufacturing, most value addition occurs in denim washing. This paper focuses on identifying and prioritizing the performance criteria of the denim washing sector in particular. In this context, export-oriented denim washing factories are chosen and the identified criteria are evaluated by using Analytical Hierarchy Process (AHP). This study is qualitative in nature and the secondary data about the factors were collected initially through review of previous literature, magazines, books, and newspapers. A structured questionnaire was developed to collect data from 35 factories. The results of the study show that cost, time, quality, and flexibility are the critical factors for success. The findings also seem to be consistent in general in regard to the test results, and it provides insight for improvement in the denim washing industry of Bangladesh.
\end{abstract}

Keywords: Analytical Hierarchy Process, Prioritization, Performance Criteria, Denim Washing Industry

\section{Introduction}

Markets for companies are rapidly changing due to globalization and technological enhancement. In this volatile market condition, designing and producing innovative products is a key factor. As a result, four criteria which are cost, quality, flexibility, and speed evolved as critical factors for success because of their significant impact on manufacturing performance. Timely 
production of low-cost products is previously assumed to affect manufacturing production but the meaning has been revisited (Ezgi Kaya, 2007).

Manufacturing performance is a necessity for manufacturing organizations to achieve their goals and objectives. Firms need to determine the performance criteria to evaluate, control, and improve the production process for measuring manufacturing performance. Performance measures can also be used to compare the performance of different organizations, plants, departments, individuals or machines.

According to Ghalayini et al. (1997), "World-class manufacturers recognize the importance of metrics in helping to define the goals and performance expectations for the organization. They adopt or develop appropriate metrics to interpret and describe quantitatively the criteria used to measure the effectiveness of the manufacturing system and its many interrelated components."

Consequently, defining the right criteria is essential to achieve the goals. The decision on manufacturing performance criteria must be parallel to the company's vision, mission statement, and strategic goals. Moreover, in a competitive environment, manufacturing organizations need to improve their products and production systems to survive. As a result of this decision making process, manufacturing performance criteria is employed. In deciding what to measure, the objectives for each organizational unit, departments, plants, and individuals must be defined. Critical success factors are determined to develop performance measures to monitor the attainment of these factors.

To prioritize the factors, a certain framework is needed. There are several ways to do this such as numerical assignment, Moscow technique, Bubble short technique, five whys, Hundred dollar method, and Analytic Hierarchy Process (A List of Requirements Prioritization Techniques You Should Know About - Business Analyst Learnings, n.d.). Among all the methods, AHP is adopted in this study because it can convert the qualitative response from respondents in a quantitative way. Moreover, it can justify the pair for comparing between the factors.

\section{Literature Review}

Due to intense competition, globalization and an explosion of technology in recent years, organizational learning, knowledge creation, and innovation capability have emerged as the dominating factors of competitive advantage (Crossan \& Berdrow, 2003). Currently, businesses must operate within a dynamic environment of fierce competition, shrinking budgets, and heavy price pressures ((Levin, 2005). Consequently, organizations deal with many key performance indicators (KPIs) in different areas. Therefore, several scholars have proposed the enhancement of traditional methods of establishing and prioritizing KPIs, and several new approaches are being proposed. Goal 
setting and feedback have proven to improve productivity. Goal-setting theory suggests that specific and challenging goals result in higher performance than moderate or easy attainable goals, vague goals or no goals at all ((Locke, 2002). To minimize the risks involved in goal setting, the prioritization of KPIs should be viewed as a multi-criteria and decision-making problem (Shahin \& Mahbod, 2007). Competitive pressures in the global manufacturing environment causes manufacturing organizations to re-engineer their strategies, structures, operations, systems, processes, and procedures to become more competitive in the marketplace. Toward that end, the management of these organizations are paying closer attention to the changing nature of manufacturing performance and the systems, processes, and measures used in its evaluation.

With the rapid introduction of new technologies and changes in the manufacturing sector, manufacturers struggle to measure and manage performance across their operations effectively. This need has given rise to the importance of a comprehensive performance management system, which would enable the manufacturers to improve all the facets of their operations and attain a competitive edge in the market (Sahoo \& Jena, 2012). Many authors have dealt with this concept by classifying competitive priorities into several categories such as quality, timeliness, flexibility, and dependability (Rangone, 1996). This result was difficult to get through traditional approaches of manufacturing performance measurement, based on cost schemes and operating efficiency measures, since they do not fit the changing role of manufacturing. For this reason, many consultants, academics, and professionals have suggested integrating financial measures with nonfinancial indices (Rangone, 1996).

The literature concerning performance measurement evolved through two phases. The first phase started in the late 1880s, while the second phase started in the late 1980s. Cost accounting orientation characterized the first phase. This orientation focused on aiding managers in evaluating the relevant costs of operating their firms. This approach was later modified in an attempt to incorporate some financial measures such as profit and return on investment (Ghalayini et al., 1997). However, even with the financial focus, this approach received considerable criticisms. Critics argued, with justification, that focusing solely on financial measures when measuring performance tends to encourage short-term thinking. This argument was further reinforced on the ground that traditional financially-based performance measurement systems failed to measure and integrate all the factors which are critical to business success (Gomes et al., 2004). Also, it is not obvious how firms should measure their manufacturing performances. Various approaches exist and most of them have a large number of measures on different hierarchical levels. Many of the measures are considered obsolete and inconsistent for various reasons. The 
usefulness of most cost accounting systems, individual measures, as well as more comprehensive activity-based costing systems are frequently questioned since they do not cover manufacturing performances relative to the competitive capabilities. Another serious problem with most performance measurement systems used in firms is that they often include too many different measures, which makes it difficult to understand the "big picture". Integration between measures is often problematic, and many papers have emphasized that firms have no effective system that covers all necessary performance dimensions. Schmenner and Vollmann (1994) showed in an empirical study that most studied companies needed to seriously consider changing their performance measurements. They argued that most firms were using wrong measures and are failing to use the right measures in correct ways. This is serious and, therefore, it seems important to identify the critical dimensions in a performance measurement system (what to measure) and the optimum characteristics of the measures (how to measure). When there are dependencies and interactions among the criteria in a decision-making model, the analytic network process is a more appropriate methodology. Nevertheless, AHP assumes linear independence of criteria and alternatives (Bayazit, 2005).

In various settings of decision making, the analytic hierarchy process has been used. The Department of Defence in the US uses it frequently and extensively to allocate their resources to their diverse activities. In 2001, it was used to determine the best relocation site for the earthquake-devastated Turkish city Adapazari. British Airways also used it in 1998 to choose the entertainment system vendor for its entire fleet of airplanes. A company used it in 1987 to choose the best type of platform to build a drill for oil in the North Atlantic. A platform costs around 3 billion dollars to build, but the demolition cost was an even more significant factor in the decision. A book was written in 1990 by Nagel and Mills titled "Multi-criteria Methods for Alternative Dispute Resolution (NY: Quorum Books)" which applies the concepts of quantitative decision making in public administration. Examination of the book shows that the authors suggest using ordinal scale numbers alongside actual numbers such as money and other measurements. A mathematician may wonder, how one can add and multiply ordinal numbers and derive priorities from them. Nevertheless, the authors were thinking in the right direction by proposing the use of multi-criteria methods. The process was applied to the US versus China conflict in the intellectual property rights battle of 1995 over Chinese individuals copying music, video, and software tapes and CDs. An AHP analysis involving three hierarchies for benefits, costs, and risks showed that the US should not sanction China. Xerox Corporation has used the AHP to allocate close to a billion dollars to its research projects. In 1999, the Ford Motor Company used the AHP to establish priorities for criteria that improve 
customer satisfaction. Ford gave Expert Choice Inc. an Award for Excellence for helping them achieve greater success with its clients. In 1986, the Institute of Strategic Studies in Pretoria, a government-backed organization, used the AHP to analyze the conflict in South Africa and recommended actions ranging from the release of Nelson Mandela to the removal of apartheid and the granting of full citizenship and equal rights to the black majority. All of these recommended actions were quickly implemented. The AHP has been used in student admissions, military personnel promotions, and hiring decisions. In sports, it was used in 1995 to predict which football team would go to the Super Bowl and win (correct outcome, Dallas won over my hometown, Pittsburgh). The AHP was applied in baseball to analyze which Padres players should be retained. IBM used the process in 1991 in designing its successful mid-range AS 400 computer. IBM won the prestigious Malcolm Baldrige award for Excellence for that effort. Bauer et al. (1992) devoted a paper on how AHP was used in benchmarking.

The analytic hierarchy process is a theory of measurement that deals with quantifiable and /or intangible criteria that have found rich applications in decision theory, conflict resolution, and in models of the brain. It is based on the principle that to make decisions, experience and knowledge of people is as valuable as the data they use (Vargas, 1990). The Analytic Hierarchy Process (AHP) is a theory of measurement through pairwise comparisons, and it relies on the judgments of experts to derive priority scales. It measures intangibles in relative terms. The comparisons were made using a scale of absolute judgments that represents how one element dominates another concerning a given attribute. The judgments may be inconsistent. Thus, how to measure inconsistency and improve the judgments to obtain better consistency is a concern of AHP (Saaty, 2008). Madu et al. (1991) referred to AHP as the most powerful and widely used technique for decision making. It allows decision makers to measure the consistency and stability of their decisions. AHP has proven to be useful in prioritizing alternative variables (Lu, 1994).

Dey and Cheffi (2013) proposed a framework to measure and benchmark the green supply chain performance of organizations using AHP and combining supply chain management, environmental management, and performance measurement. This study, therefore, develops an innovative GSC performance measurement framework by integrating supply chain processes (supplier relationship management, internal supply chain management, and customer relationship management) with organizational decision levels (both strategic and operational). Environmental planning, environmental auditing, management commitment, environmental performance, economic performance, and operational performance are the key level constructs. The proposed framework was applied to three selected manufacturing 
organizations (car, cement, and carpet) in the UK. Their GSC performance was measured and benchmarked by using the analytic hierarchy process (AHP), which is a multiple-attribute decision-making technique. The AHPbased framework offers an effective way to measure and benchmark the GSC performance of organizations. This study has both theoretical and practical implications. Theoretically, it contributes holistic constructs for designing a GSC and managing it for sustainability. Practically, it helps industry practitioners to measure and improve the environmental performance of their supply chain (Dey \& Cheffi, 2013). Lee et al. (2018) analyzed the key criteria that are responsible for sustainable development for traditional manufacturing in Taiwan with the help of the following tools: AHP, Decision making trial, and evaluation laboratory (DEMAETAL). The results of the study suggest that Taiwan should focus on design and innovation.

Information on the use of AHP in assessing advanced manufacturing technologies was provided and an AHP model was also recommended to guide the management of tractor manufacturing plant. Most importantly, their relative importance and influences on the objective of the decision-making model was found. By performing a sensitivity analysis, it was also found that the outcome remained stable in all cases when the weights of the main criteria affecting the decision varied up and down by 5 percent in all possible combinations. Results suggested that the tractor manufacturing company should implement FMS (Flexible Manufacturing System) in the entire plant (Gomes et al., 2004).

The automated manufacturing system was viewed as the computerbased system, which can facilitate the improvement of the total productivity of the organization concerning product design and development, manufacturing, and other support functions. There are three types of automated manufacturing systems, namely CAD, CAD-FMM, and CADCAM. The study on an Indian power manufacturing and distribution company (transformer manufacturing company) showed that they were struggling to choose which AMS to adopt. After selecting the criteria (Technological, social, strategic) under each of the three alternatives (CAD, CAD-FMM, CAD-CAM), AHP analysis was performed and CAD was prioritized (Venkataraman, 1993). A software-based tool was proposed to evaluate the manufacturing performance of Malaysian automotive small and medium enterprises using AHP where five factors with 25 dimensions were proposed. This can be used to identify the strength and weakness that indicates where and how much improvement needs to be made. The evaluation tool was then tested in two Malaysian automobiles SME where both companies concluded the proposed tool was suitable, implementable, uncomplicated, and it could be used in a real working environment (Yusof, 2010). The application of AHP to prioritize the manufacturing performance criteria in the textile industry in 
Turkey suggested the textile sector's improvement and provided foresight for future growth.

However, little attention has been given so far to the application of AHP to prioritize performance criteria of labor-intensive industries such as RMG, Knitting, Weaving, Spinning, Denim, Washing, etc. The Economy of Bangladesh is mostly dependent on the industries mentioned earlier. This is because they contribute around $80 \%$ to total export value and on the consistent growth of the GDP at the same time (RMG Is the Prime Export Oriented Industrial Sector of Bangladesh, n.d.). Thus, this paper focuses on identifying the key operational performance criteria of the most value-added industryDenim washing. Also, it helps to prioritize them according to the importance that will help managers in better decision making among the alternatives.

\section{Methodology}

The first steps of this study involve identifying the criteria and subcriteria for manufacturing performance evaluation. The manufacturing performance measures were identified and adapted from the literature study.

Thereafter, a survey was conducted in denim washing industries in Bangladesh to match the measures that were practiced in the industry. Through the survey, the measures were modified. After some revision, four (4) factors with 23 dimensions have been proposed as manufacturing performance measures. The proposed measures are used as manufacturing performance criteria as shown in the table below.

Table 1. Selection of criteria and sub-criteria

\begin{tabular}{|l|l|l|l|}
\hline \multicolumn{1}{|c|}{ Cost } & \multicolumn{1}{|c|}{ Time } & \multicolumn{1}{c|}{ Quality } & \multicolumn{1}{c|}{ Flexibility } \\
\hline Material Cost & Cycle Time & Material Quality & Lot Size \\
Overhead Cost & R\&D Time & Test Parameter & New tech. \\
Inventory Cost & Rework Time & Skilled Manpower & Responds to Product - \\
M/C Cost & Approval Time & Vendors Quality - & Mix Changes \\
Direct Labour Cost & Paperwork Time & Rework & The economic value of \\
R\&D Cost & M/C set up Time & Conformance to -spec. & Lot \\
Rework Cost & & & \\
\hline
\end{tabular}

While taking responses from experts, the respondent's profiles were considered (Age, Education, Experience, and Designation). Since AHP is a decision-making tool, this study has considered the response of only decision makers. In general, mid-level management and above are counted as decision makers. Therefore, in this study, respondents with designation assistant manager and above, experience with 8 years and above, and education qualification with Textile engineering and above were considered.

Finally, the second questionnaire was developed to collect a pair-wise comparison of selected criteria and sub-criteria from sample factories. Comparison matrix and normalized matrix were created using the pair-wise 
comparison feedback from comparison questionnaire, and weight was calculated for four (4) prime criteria along with 23 dimensions for all 35 sample industries which summed up to 165 matrices.

For justification of pair-wise comparison, whether they are consistent or not, a consistency test was done.

$$
\begin{aligned}
& C I=\frac{(\lambda \max -n)}{(n-1)} \\
& C R=\frac{C I}{R I}
\end{aligned}
$$

Where $\lambda \max =$ Average of weight from normalized matrix

$$
\begin{aligned}
\mathrm{n} & =\text { Size of matrix } \\
\mathrm{CI} & =\text { Consistency index } \\
\mathrm{RI} & =\text { Random index from Saaty scale } \\
\mathrm{CR} & =\text { Consistent ratio }
\end{aligned}
$$

If the value of $\mathrm{CR}<0.10$, then the pair-wise comparison is consistent.

\section{Results and Discussion}

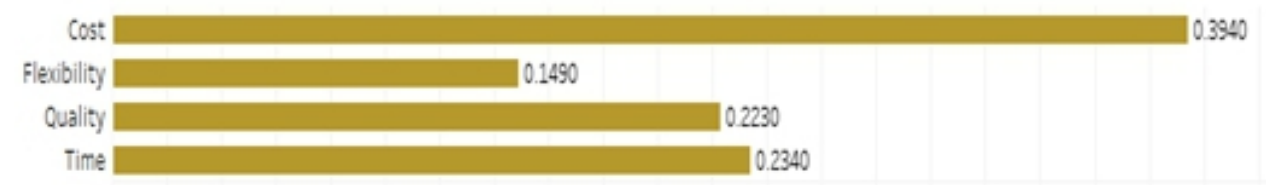

$\begin{array}{lllllllllllllllllllll}0.02 & 0.04 & 0.06 & 0.08 & 0.10 & 0.12 & 0.14 & 0.16 & 0.18 & 0.20 & 0.22 & 0.24 & 0.26 & 0.28 & 0.30 & 0.32 & 0.34 & 0.36 & 0.38 & 0.40 & 0.42\end{array}$ Percentage

Figure 1. Weight of main criteria by AHP

From the results of the study, it can be stated that the firms were examined to show the behaviors of a typical textile firm. The most important criteria are cost (39.4). More so, among cost components, material cost got the highest weight (23.99). Among time components, R\&D time is top-ranked with weight (35.4). The test parameter is the top-ranked criteria within the quality dimension alongside weight (25.4). Among the flexibility dimensions, new technology got the highest weight (43.1).

Among all the four (4) prime criteria, cost gained the highest weight while flexibility gained the lowest. To ensure sustainability in today's competitive global market and to be able to meet uncertain customer demand, more focus should be on flexibility. There are no alternatives to be more flexible to lead this business with the usage of cutting edge technology. 


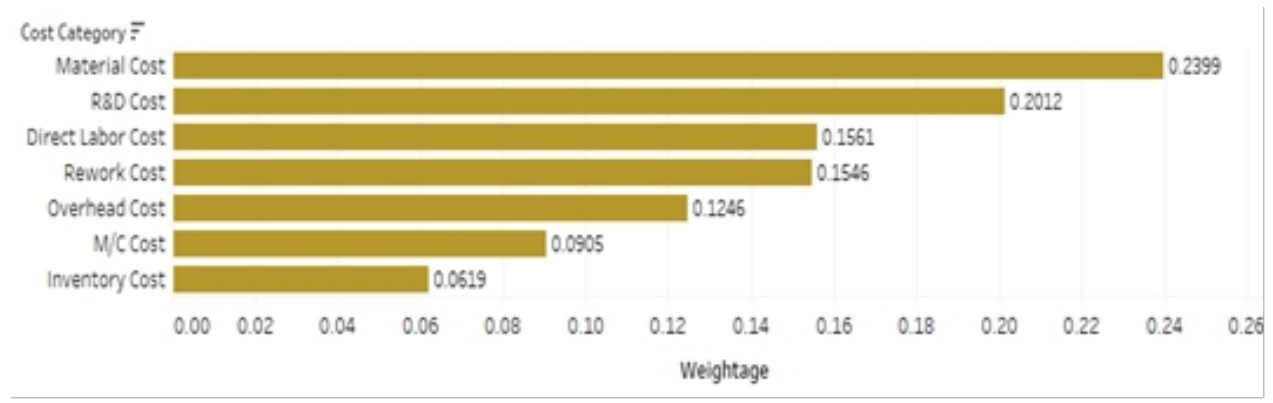

Figure 2. Weight of cost components by AHP

A great portion (around 25\%) of the total product cost goes to material cost. This sector is fully dependent on imported raw materials (Cotton, chemicals, etc). If there is a supportive backward linkage industry, the cost of material may go down. Direct labor cost has a decent amount of weight (15.6). This industry has a lot of advantages of cheap labor costs in Bangladesh, but the upcoming scenario will be reversed. It is high time to lower the focus from cheap labor and go for the value-added product. As a result of this development, the cost may get better attention. About $60 \%$ of finished products go through the rework process because of improper process, machine failure, and defects of raw materials. There is a huge opportunity to lower rework costs by appropriate machines, materials, and cycle time.

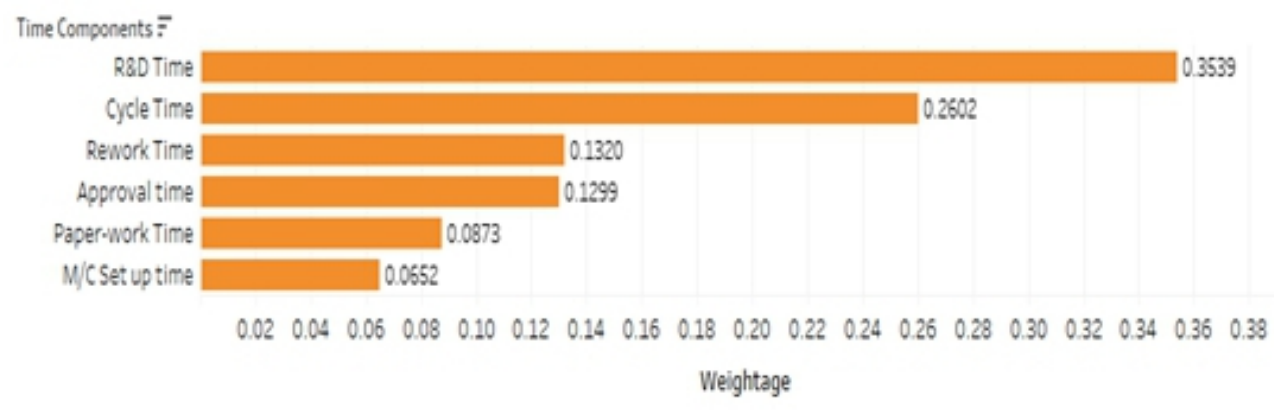

Figure 3. Weight of time components by AHP

In addition, development time (Sample) receives too much importance than other components of time. Product development is done in two ways, namely R\&D and design. Sample development in denim washing is done by designing where there are little rooms for R\&D. Development time (by designing) should get lower weight. Rework time weight (13.2) can be lowered by utilizing the right material, machines, and manpower. However, it cannot be lowered to zero since producing $100 \%$ quality products is almost impossible to some extent. 


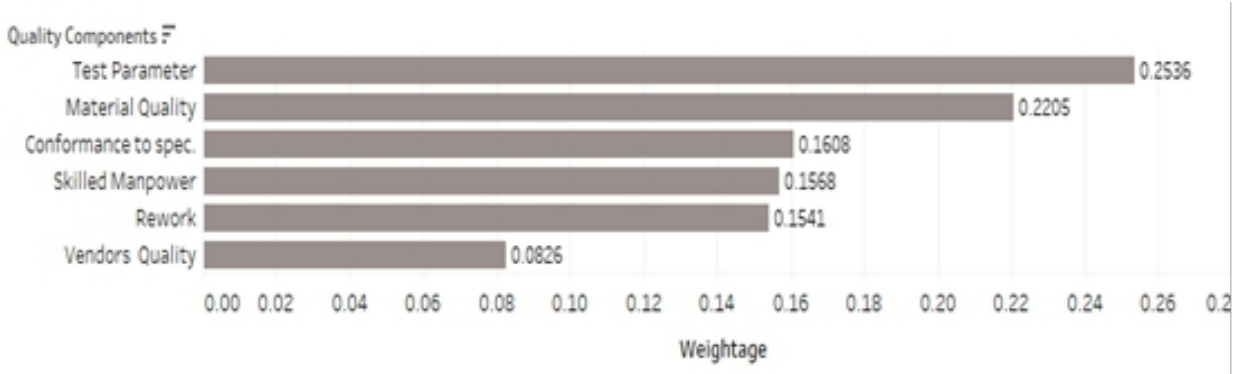

Figure 4. Weight of quality components by AHP

Material quality (22.1) and skilled manpower (15.7) are important for better performance of denim washing industries in terms of quality perspective. On the other hand, rework has weight (15.4) which seems a little contradictory. As industries provide enough attention to material quality and skilled manpower, rework should not get any attention. This is because rework suggests that industries are not maintaining proper material quality and manpower.

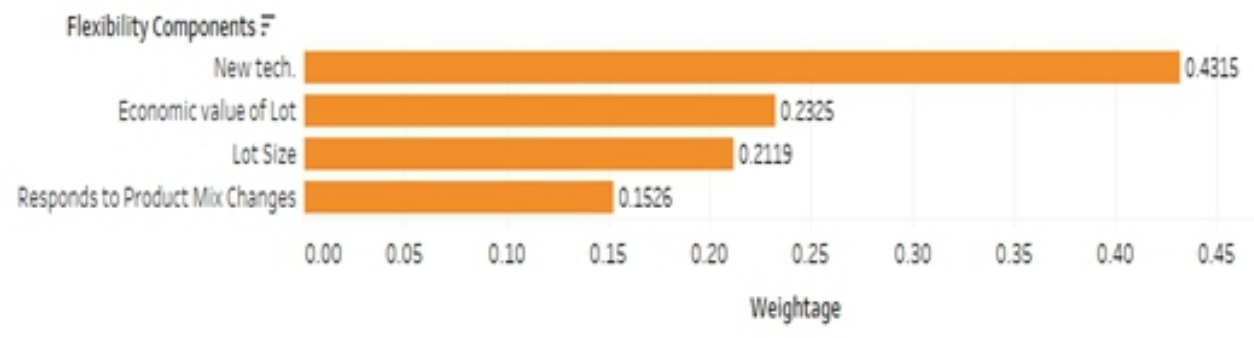

Figure 5. Weight of flexibility components by AHP

The economic value of the lot and lot size receives almost equal importance. Also, new technology is getting the highest weight (43.1). Installation of new technology can make a certain denim washing firm to be flexible in response to product mix changes, while the response to product mix changes gains weight (15.3).

After putting the feedback from pair-wise comparison to comparison matrix and normalization, weight for each criterion was computed for all the listed sample industries. Finally, the average weight for any criteria was calculated with the formula below:

$\mathrm{a}=\left(\sum \mathrm{w}\right) / \mathrm{n}$

Where $\mathrm{w}=$ weight of any specific criteria

$\mathrm{n}=$ number of factories

$\mathrm{a}=$ avg. weight

Total score $=\sum A * B$ 
Where, $A=$ Average weight of a particular criteria

$\mathrm{B}=$ Individual score of any industry for those particular criteria factories, which got the highest score, ranked as one and vice-versa.

Table 2. Ranking of respondent factories

\begin{tabular}{|c|c|c|c|c|c|c|c|c|c|c|c|c|c|c|c|c|c|}
\hline Factory & $\varangle$ & 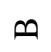 & U & D & 디 & 工 & 0 & I & • & $\neg$ & $\forall$ & 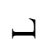 & $\Sigma$ & Z & 0 & 2 & 0 \\
\hline Total & 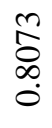 & $\begin{array}{l}\infty \\
\infty \\
\infty \\
\infty \\
0\end{array}$ & $\begin{array}{l}\hat{n} \\
\hat{\alpha} \\
0\end{array}$ & $\begin{array}{l}n \\
\infty \\
\infty \\
\infty \\
0\end{array}$ & $\begin{array}{l}\overline{0} \\
\infty \\
\infty \\
0\end{array}$ & $\begin{array}{l}\infty \\
2 \\
\infty \\
\infty \\
0\end{array}$ & $\begin{array}{l}\infty \\
\stackrel{\infty}{\infty} \\
\dot{\infty} \\
0\end{array}$ & $\begin{array}{l}\infty \\
\infty \\
\infty \\
\infty \\
0\end{array}$ & $\begin{array}{l}\bar{a} \\
\infty \\
0 \\
0\end{array}$ & $\begin{array}{l}\infty \\
\infty \\
\infty \\
0 \\
0\end{array}$ & $\begin{array}{l}= \\
\infty \\
\infty \\
0 \\
0\end{array}$ & 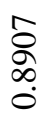 & $\begin{array}{l}\hat{\circ} \\
\hat{\circ}\end{array}$ & $\begin{array}{l}n \\
\stackrel{2}{ } \\
\infty \\
0\end{array}$ & $\begin{array}{l}\frac{a}{0} \\
\frac{a}{0}\end{array}$ & 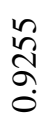 & $\begin{array}{l}0 \\
\text { ڤे } \\
\vdots \\
0\end{array}$ \\
\hline Rank & 35 & 34 & 15 & 18 & 26 & 27 & 23 & 22 & 24 & 25 & 21 & 16 & 12 & 17 & 10 & 6 & 5 \\
\hline Factory & $n$ & $\mapsto$ & $\triangleright$ & $>$ & 3 & $x$ & $\succ$ & $N$ & 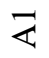 & $\bar{n}$ & $\bar{U}$ & $\overline{0}$ & $\bar{I}$ & $\bar{I}$ & $\bar{U}$ & $\bar{I}$ & $\Xi$ \\
\hline Total & $\begin{array}{l}\stackrel{m}{+} \\
\text { ¿े }\end{array}$ & $\begin{array}{l}\text { مे } \\
\infty \\
\infty \\
0\end{array}$ & $\begin{array}{l}\stackrel{2}{\infty} \\
\stackrel{+}{0}\end{array}$ & $\frac{\hat{m}}{a}$ & $\begin{array}{l}\infty \\
\stackrel{\circ}{\circ} \\
\stackrel{\circ}{0}\end{array}$ & 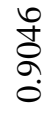 & $\begin{array}{l}\hat{\widehat{o}} \\
\text { }\end{array}$ & 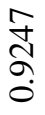 & $\begin{array}{l}\text { तै } \\
\text { ડ̦ } \\
\stackrel{0}{0}\end{array}$ & $\begin{array}{l}\bar{m} \\
\stackrel{5}{0}\end{array}$ & $\begin{array}{l}\nabla \\
\infty \\
\infty \\
0\end{array}$ & $\begin{array}{l}\text { î } \\
\text { \&. } \\
0 \\
0\end{array}$ & $\begin{array}{l}\text { Y } \\
\text { 官 } \\
0 \\
0\end{array}$ & $\begin{array}{l}\vec{n} \\
n \\
0 \\
0\end{array}$ & $\begin{array}{l}\text { Oे } \\
\stackrel{0}{\infty} \\
\dot{0} \\
\dot{0}\end{array}$ & $\begin{array}{l}\tilde{a} \\
\text { ळo } \\
\dot{0}\end{array}$ & $\begin{array}{l}\text { J } \\
\text { J } \\
\stackrel{0}{0}\end{array}$ \\
\hline Rank & 2 & 20 & 1 & 9 & 11 & 13 & 14 & 7 & 8 & 3 & 19 & 28 & 29 & 30 & 31 & 33 & 32 \\
\hline
\end{tabular}

The AHP calculation shows that the top-ranked factory is (U) with an overall weight (0.9489), which is less consistent. This is because its consistency ratio is high in comparison to the bottom-ranked factory (A) with an overall weight $(0.8073)$, which is more consistent since the consistency ratio is low. The industry with the highest score can be an example for others in this sector.

In this study, consistency test results dispense deeper insights about performance criteria.

Table 3. Descriptive statistics of the consistency test of cost components

\begin{tabular}{|l|r|r|r|r|r|r|}
\hline & \multicolumn{1}{|c|}{$\mathrm{N}$} & \multicolumn{1}{c|}{ Minimum } & Maximum & \multicolumn{1}{c|}{ Sum } & \multicolumn{1}{c|}{ Mean } & Std. Deviation \\
\hline Cost & 35 & .002 & .107 & 2.290 & .06543 & .031479 \\
Valid N (listwise) & 35 & & & & & \\
\hline
\end{tabular}

Table 3 reveals that the minimum value is 0.002 , while the maximum value is 0.107 with a standard deviation of 0.031479 from the mean value of 0.06543 .

Table 4. Descriptive statistics of the consistency test of time components

\begin{tabular}{|l|r|r|r|r|r|r|}
\hline & \multicolumn{1}{|c|}{$\mathrm{N}$} & \multicolumn{1}{c|}{ Minimum } & Maximum & \multicolumn{1}{c|}{ Sum } & \multicolumn{1}{c|}{ Mean } & Std. Deviation \\
\hline Time & 35 & .050 & .109 & 2.904 & .08297 & .016314 \\
Valid N (listwise) & 35 & & & & & \\
\hline
\end{tabular}

Table 4 shows that the minimum value is 0.050 , while the maximum value is 0.109 with a standard deviation of 0.016314 from the mean value of 0.0897 . 
Table 5. Descriptive statistics of the consistency test of quality components

\begin{tabular}{|l|r|r|r|r|r|r|}
\hline & \multicolumn{1}{|c|}{$\mathrm{N}$} & \multicolumn{1}{c|}{ Minimum } & Maximum & \multicolumn{1}{c|}{ Sum } & \multicolumn{1}{c|}{ Mean } & Std. Deviation \\
\hline Quality & 35 & .028 & .110 & 2.980 & .08514 & .019768 \\
Valid N (listwise) & 35 & & & & & \\
\hline
\end{tabular}

Table 5 reveals that the minimum value is 0.028 , while the maximum value is 0.11 with a standard deviation of 0.01976 from the mean value of 0.08514 .

Table 6. Descriptive statistics of the consistency test of flexibility components

\begin{tabular}{|l|r|r|r|r|r|r|}
\hline & \multicolumn{1}{|c|}{$\mathrm{N}$} & \multicolumn{1}{c|}{ Minimum } & Maximum & \multicolumn{1}{c|}{ Sum } & \multicolumn{1}{c|}{ Mean } & Std. Deviation \\
\hline Flexibility & 35 & .021 & .110 & 2.940 & .08400 & .023072 \\
Valid N (listwise) & 35 & & & & & \\
\hline
\end{tabular}

Table 6 shows that the minimum value is 0.021 , while the maximum value is 0.11 with a standard deviation of 0.02307 from the mean value of 0.0840 .

The consistency ratio of cost components is the lowest among all, but it is (weight) most likely to vary since its standard deviation is the highest. Consequently, the consistency ratio of time components is the highest, but it is (weight) most likely to be similar throughout the industry since its standard deviation is the lowest. Since all these criteria are within the consistency limit, they provide valid insights.

\section{Conclusion}

The study results show that cost stands out among other measures, while quality and time represent similar measures. A detailed examination indicates a wide gap between the studied criteria. Material cost is measured to be 0.23 and $R \& D$ cost is measured to be 0.20 , while machine cost and inventory cost is measured to be 0.09 and 0.06 respectively. R\&D time and cycle time is measured to be 0.35 and 0.26 . However, paper-work time and machine set up time indicate 0.08 and 0.06 .

This study helps to identify strengths and weaknesses and can point out where improvement is necessary. The decision makers of the factories can get a better insight into the criteria which are more relevant than others to achieve organizational goals.

AHP is a subjective model, which is dependent on the personal opinions of the researchers. To overcome this difficulty, the opinions of decision makers of the firms were taken separately and the mean of these opinions was used in the study. However, this may still render the research subjective. Another limitation of the study is the criteria.

Defining criteria and categorizing it confines the study. Literature about performance measurement in the textile sector is very limited. Thus, this 
study points out the deficiency of literature. An important point to take note of is that the firms operating in Bangladesh textile sector are working as contractors. Therefore, design is not considered as a critical aspect, and it produces goods that are designed in other countries. While producing these products, the foreign headquarters of the firms send all the product specifications. Hence, the examined firm does not consider design as an important criterion that reflects this point of view in the sector.

In future studies, expanding this analysis is possible by combining more criteria and relevant sub-criteria. Sample factories considered in this study are from Savar, Gazipur, and Narayangonj zone. In the future, more factories from Chittagong and other parts of the country can be included for the generalization of the result.

This kind of research is rare in the denim sector of developing countries. This study also contributes to the existing field of knowledge by providing a validated index of performance criteria of the denim washing sector of Bangladesh.

Despite the fact that the research is confined to the denim washing industry of Bangladesh only, insights will have a closer implication on other relevant industry too. This study will provide an opportunity for benchmarking in the denim washing sector and generalization for the firms that operate in this sector in order to identify and implement performance criteria and be competitive in the homogenous sector worldwide.

\section{References:}

1. A-List of Requirements Prioritization Techniques You Should Know About - Business Analyst Learnings. (n.d.). Retrieved June 27, 2020, from https://businessanalystlearnings.com/blog/2016/8/18/a-list-ofrequirements-prioritization-techniques-you-should-know-about

2. Bayazit, O. (2005). Use of AHP in decision-making for flexible manufacturing systems. Journal of Manufacturing Technology Management, 16(7), 808-819.

https://doi.org/10.1108/17410380510626204

3. Crossan, M. M. \& Berdrow, I. (2003). Organizational learning and strategic renewal. Strategic Management Journal, 24(11), 1087-1105. https://doi.org/10.1002/smj.342

4. Dey, P. K. \& Cheffi, W. (2013). Green supply chain performance measurement using the analytic hierarchy process: A comparative analysis of manufacturing organizations. Production Planning and Control, 24(8-9), 702-720.

https://doi.org/10.1080/09537287.2012.666859

5. Ezgi Kaya, F. D. (2007). Manufacturing Performance Criteria: An AHP Application in a Textile Company. PICMET. 
6. Ghalayini, A. M., Noble, J. S., \& Crowe, T. J. (1997). An integrated dynamic performance measurement system for improving manufacturing competitiveness. International Journal of Production Economics, 48(3), 207-225. https://doi.org/10.1016/S09255273(96)00093-X

7. Gomes, C. F., Yasin, M. M., \& Lisboa, J. V. (2004). A literature review of manufacturing performance measures and measurement in an organizational context: A framework and direction for future research. Journal of Manufacturing Technology Management, 15(6), 511-530. https://doi.org/10.1108/17410380410547906

8. Lee, Z. Y., Chu, M. T., Chen, S. S., \& Tsai, C. H. (2018). Identifying comprehensive key criteria of sustainable development for traditional manufacturing in Taiwan. Sustainability (Switzerland), 10(9). https://doi.org/10.3390/su10093275

9. Levin, B. (2005). Success factors goal management. www.successfactors.com/product/GoalManagement

10. Locke, E. A. (2002). No Title Building a practically useful theory of goal setting and task motivation. American Psychologist, 57(9), 705715.

11. Lu, M. M. (1994). Integrating QFD, AHP, and benchmarking in strategic marketing. Journal of Business \& Industrial Marketing, 9(1), 41-50.

12. Rangone, A. (1996). An analytical hierarchy process framework for comparing the overall performance of manufacturing departments. International Journal of Operations and Production Management, 16(8), 104-119. https://doi.org/10.1108/01443579610125804

13. $R M G$ is the prime export-oriented industrial sector of Bangladesh (n.d.). Retrieved June 27, 2020, from http://textilefocus.com/rmgindustry-outlook-2019/

14. Saaty, T. L. (2008). Decision making with the analytic hierarchy process. Int. J. Services Sciences, 1(1).

15. Sahoo, C. K. \& Jena, S. (2012). Organizational performance management system: Exploring the manufacturing sectors. Industrial and Commercial Training, 44(5), 296-302. https://doi.org/10.1108/00197851211245059

16. Shahin, A. \& Mahbod, M. A. (2007). Prioritization of key performance indicators: An integration of the analytical hierarchy process and goal setting. International Journal of Productivity and Performance Management, 56(3), 226-240. https://doi.org/10.1108/17410400710731437

17. Vargas, L. G. (1990). An overview of the analytic hierarchy process and its applications. European Journal of Operational Research, 
48(1), 2-8. https://doi.org/10.1016/0377-2217(90)90056-H

18. Venkataraman, R. M. (1993). Use of Analytic Hierarchy Process for Selecting an Automated Manufacturing System. IJOPM, 13(8), 45-57.

19. Yusof, E. A. (2010). Manufacturing Performance Evaluation Tool for Malaysian Automotive Small and Medium-sized Enterprises. International Journal of Business and Management Science, 3(2), 195-213. 